\title{
Afirmacja zmiany. Uwagi o wpływie technologii cyfrowych na literaturoznawstwo ${ }^{1}$
}

Marek Kaźmierczak

TEKSTY DRUGIE 2020, NR 1, S. 268-274

DOI: $10.18318 /$ td.2020.1.16 | ORCID: 0000-0002-4913-2149

$\mathbf{M}$

onografia Cyfrowa semiopoetyka została wydana jako XLI tom w serii Nowa Humanistyka przez Wydawnictwo Instytutu Badań Literackich PAN w 2018 roku. Książka składa się z dwóch części. Pierwsza z nich, Fenomenologia i epistemologia cyfrowości, wprowadza czytelnika w zagadnienia, które będą szczegółowo omawiane w kolejnych rozdziałach. Druga część, Znak - tekst - dyskurs. Cyfrowe reprezentacje struktur, jest pełnym metodologicznie i poznawczo wykładem koncepcji Autorki. Część pierwsza monografii zawiera jeden rozdział zatytułowany Cyfrowy światoobraz. System cyfrowy i jego wyznaczniki. Część druga monografii składa się z sześciu rozdziałów traktujących o powtarzalności i dynamice struktury (rozdział drugi), cyfrowym przemodelowaniu znaku (rozdział trzeci), o istocie i własnościach cyfrowej semiosfery (rozdział czwarty), o digitalnie uwarunkowanym przemodelowaniu w sferze tekstu (rozdział piąty), o strategiach

1 Recenzja książki E. Szczęsnej Cyfrowa semiopoetyka, Wydawnictwo IBL PAN, Warszawa 2018.

\author{
Marek \\ Kaźmierczak pra- \\ cuje na stanowisku \\ profesora uczelnia- \\ nego, jest zatrud- \\ niony w Instytucie \\ Filmu, Mediów i Sztuk \\ Audiowizualnych \\ Wydziału Filologii \\ Polskiej i Klasycznej \\ UAM. Bada film, me- \\ dia cyfrowe i kulturę \\ współczesną w kon- \\ tekście myślenia \\ potocznego i antro- \\ pologii codzienności. \\ Jest autorem licznych \\ prac na temat \\ recepcji Zagłady \\ w kulturze popularnej \\ i w Internecie. Współ- \\ twórca Laboratorium \\ semiotycznego na \\ Wydziale „Artes \\ Liberales" UW oraz \\ Ośrodka Badań nad \\ Komunikowaniem im. \\ McLuhana UAM.
}


znaczeniotwórczych, cyfrowych reprezentacjach figur i narracji zapośredniczonej digitalnie (rozdział szósty), a także o przestrzeniach dyskursu (rozdział siódmy). Książka zawiera bogatą bibliografię, netografię, notę bibliograficzną, streszczenie w języku angielskim oraz indeks nazwisk. Na szczególne wyróżnienie zasługuje indeks rzeczowy będący spisem najważniejszych pojęć, pełniącym funkcję słownika, który okazuje się warunkiem sine qua non dla formującej się tożsamości nowej dyscypliny naukowej, tj. cyfrowej semiopoetyki. Autorka wiele razy podkreśla w książce konieczność wypracowania terminologii adekwatnej do badania zmiennej komunikacyjnie rzeczywistości, pisząc m.in.: „Systemowo-syntagmatyczny porządek dyskursu digitalnego wskazuje na możliwość jego opisu przy użyciu kategorii zastanych, choć wymagających niekiedy reinterpretacji" (s. 37). Odbiorca w trakcie czytania monografii może zatem korzystać ze słownika, wracając do kluczowych pojęć i nie tracąc przy tym płynności lektury.

Ewa Szczęsna na ponad czterystu stronach monografii przekonuje czytelnika, że wszechobecne cyfrowe technologie są s z a n s ą dla humanistyki, „szansą na jej rozwój, na wyjście poza teorie końca, śmierci, kolejnych «po-» $\mathrm{i}$ «post-» w stronę tworzenia nowych form tekstowych i dyskursywnych oraz ich badania, nazywania i problematyzowania" (s. 428). Autorka nie podważa dokonań poprzedników, podkreśla jedynie konieczność afirmatywnego nastawienia wobec przemian o charakterze technologicznym, a szerzej, cywilizacyjnym, badając ich wpływ na odchodzenie w humanistyce od paradygmatu logocentrycznego.

Zachęcam do lektury monografii Cyfrowa semiopoetyka przynajmniej na dwóch poziomach. Po pierwsze, proponuję, by czytać tę pracę jako dzieło wprowadzające nową dyscyplinę wiedzy - cyfrową semiopoetykę. Po drugie, sugeruję, aby potraktować monografię Autorki jako ważny traktat o połączeniu znaczeń i technologii (stąd tak kluczowa w jej badaniach teza o znaku cyfrowym, czyli traktat na temat przemian cywilizacyjnych, których jesteśmy uczestnikami.

Rozwój technologii cyfrowych spowodował, że komunikowanie międzyludzkie zapośredniczone medialnie stało się ramą modelującą codzienność niemal każdego człowieka. Zapośredniczenie oznacza w tym kontekście oddziaływanie narzędzi na znaki, teksty, dyskursy oraz ich współistotność w procesach tworzenia i przekazywania znaczeń. Jedną z ważniejszych konsekwencji takiej sytuacji jest zmiana statusu odbiorcy (użytkownika/czytelnika/widza/bricoleura), który coraz aktywniej współtworzy przekazy, a jednocześnie „ulega” na poziomie epistemicznym 


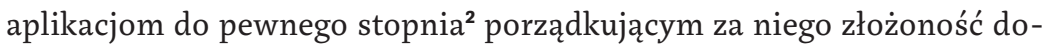
świadczeń komunikacyjnych.

Na obecnym etapie dociekań naukowych rozstrzygnięcia Autorki są kluczowe, gdyż kompleksowo opisuje ona zależności między znakiem cyfrowym, tekstem i dyskursem, wprowadzając własne ustalenia i typologie. Jestem przekonany, że wiele z tych rozstrzygnięć zacznie funkcjonować w nauce. Ewa Szczęsna, zachowując dystans badawczy, unika przewartościowania chwilowych trendów, a jednocześnie nie gmatwa się w powtarzanie ustaleń, które ongiś były ważne, ale dziś ich znajomość nie musi determinować namysłu naukowego.

W książce Cyfrowa semiopoetyka zaproponowana jest refleksja literaturoznawcza, w której na poetykę spogląda się z perspektywy semiotycznej i technologicznej, dlatego „Znak, tekst i dyskurs są analogicznymi strukturami relacji" (s. 77). Jest to założenie fundamentalne, które przybliża nas do koncepcji znaku, a jednocześnie odzwierciedla specyfikę cyfrowej semiopoetyki jako dyscypliny naukowej. W ten sposób uwzględnia trzy wzajemnie warunkujące się porządki odniesienia: interpretację, przedmiot oraz podmiot. Uwzględnijmy jednak w tym kontekście współoddziaływanie znaczeń (aspekt interpretacyjny), przedstawień (aspekt przedmiotowy) i działań (aspekt podmiotowy). Struktury relacji oznaczają dynamikę, w której na różnych poziomach złożoności oddziałują na siebie: znak, tekst i dyskurs ze względu na przedstawienia, znaczenia i działania. Proponowana koncepcja nie zostaje wyprowadzona $\mathrm{z}$ arbitralnie przyjętych założeń, lecz wynika ze specyfiki nośnika każdego z tych porządków - czyli technologii cyfrowej uruchamiającej sieć „,wzajemnych powiązań między znakiem, tekstem i dyskursem”. Tak pojmowana sieć sprawia, że „każda zmiana w sferze któregokolwiek elementu struktury będzie mieć wpływ na pozostałe jej składniki" (s. 79). Jeśli chcemy rozumieć, co dzieje się w perspektywie makrospołecznej, zastanówmy się, jak działa i jak jest zbudowany znak cyfrowy, na którego specyfikę wpływ ma cyfrowa technologia. I odwrotnie. Autorka wprowadza dwa poziomy znaku cyfrowego: poziom użytkowania i poziom programowania, aby wyjaśnić zależności między podmiotem a wykorzystywaną przez niego technologią. Poziom użytkowania, który dla Autorki okazuje się

2 Tego typu zjawiska Kazimierz Krzysztofek określa „algorytmizacją myślenia”. Por. K. Krzysztofek Status przemysłów kultury: między ekonomiq i kulturq, w: Perspektywy badań nad kulturq, red. R.W. Kluszczyński, A. Zeidler-Janiszewska, Wydawnictwo Uniwersytetu Łódzkiego, Łódź 2008 , s. 215. 
podstawowy, charakteryzowany jest przez konstytutywne aspekty znaku: aspekt zewnętrznej manifestacji (tekstura), aspekt semantyczny, aspekt działań, w który wpisane są jeszcze: działania mediacyjne i działania operacyjne. Poziom programowania, czyli tzw. poziom informatyczny, konstytuowany jest przez aspekt meta, który służy definiowaniu i projektowaniu znaku. Organizatory, modyfikatory i semantyki to znaki służące „organizacji” przekazu na poziomie aplikacji, której nie widać, a która modeluje poziom użytkowania. Uważam, że rozdziały drugi (Powtarzalność i dynamika struktury. Nieusuwalność interpretacji) i trzeci (Przemodelowanie w sferze znaku) są kluczowe w prezentowanej koncepcji znaku. Ewa Szczęsna omawia wymienione powyżej elementy, poziomy i aspekty, pokazując, co w związku z zaproponowaną koncepcją znaku cyfrowego wynika dla figur stylistycznych, hipertekstów literackich, spójności tekstu, narracji czy dyskursu kształcenia.

Przemodelowanie w sferze znaku oznacza istotne i nieobserwowane wcześniej zmiany w strukturach tekstowych, a w związku z tym - w działaniach wpisanych w teksty i w działaniach na tekstach. Ważnym pojęciem w tym kontekście jest pojęcie tekstury i jej funkcji. Konstytutywne dla tekstury wymiary technologiczny (jest tworzona m.in. za pomocą fotografii, technik audialnych, audiowizualnych i interaktywnych, w tym coraz częściej cyfrowych) i formalny (jest nośnikiem znaczeń gatunkowych) zostają opisane z uwzględnieniem postrzegania zmysłowego, zresztą Autorka wielokrotnie uświadamia czytelnikowi konieczność odwoływania się do porządku somatycznego w procesie cyrkulacji znaczeń, tekstów i dyskursów, stąd tak ważne w pracy nawiązania m.in. do badań kognitywnych.

Cyfrowa ontyczność znaku determinuje zmiany w teksturze jako „medium znaczeń" (s. 145), powodując, że jej elementy stają się ruchome, podmienialne. Są to istotne ustalenia, które wzmacniają przekonanie użytkownika wynikające z jego praktyk komunikacyjnych i kulturowych podkreślających wpływ technologii cyfrowych na znaki, na teksty i na dyskursy. Ewa Szczęsna pisze: „W erze internetu powszechność codziennych działań na cyfrowej teksturze jest koniecznym warunkiem fortunnego uczestnictwa w życiu społecznym - staje się stylem życia. Wzmocnieniu ulega podmiotowa funkcja tekstury; pełni ona nie tylko funkcję transparentnego medium znaczeń, ale jest także nośnikiem znaczeń metatekstowych, informacji gatunkowej materią tekstury nadbudowanej oraz narzędziem tekstowym" (s. 145). Tak pojmowana tekstura i jej obecność w codziennych działaniach komunikacyjnych, w interakcjach użytkownika i komputera prowadzi więc w sposób jednoznaczny do stwierdzenia, że jedną z jej najważniejszych funkcji jest 
funkcja „narzędzia tekstowego” (s. 148). Dyskurs literacki przybliża się do dyskursu gry z powodu opisanych własności cyfrowej tekstury. Można by powiedzieć, że technologie digitalne powodują, iż poszczególne porządki dyskursywne stają się - w ujęciu cyfrowej semiopoetyki - czymś więcej niż tylko poznawczymi metaforami, a jest to możliwe z powodu wspólnej im podstawy ontycznej. Tytuł monografii ściśle przylega do jej zawartości. Jest to bowiem traktat z zakresu poetyki, która wynika ze znaku cyfrowego, stąd prefiks „semio", uwarunkowanego technologicznie, dlatego przymiotnik "cyfrowa" (por. m.in. s. 409).

Czytam recenzowaną książkę i wiem, że konsekwentnie opisany i zdefiniowany znak cyfrowy zmienia zatem wszystko, co ważne w perspektywie tradycyjnych semiotyk i tradycyjnych poetyk stosowanych w badaniu komunikacji literackiej, a szerzej - tekstualnej. Dlatego wyraźne w pracy jest nastawienie afirmatywne wobec zmian determinowanych przez rozwój i oddziaływanie technologii digitalnych będących „szansą" na rozwój humanistyki bez ryzyka utraty tożsamości poznawczej.

Koncepcja znaku cyfrowego Ewy Szczęsnej - wyprowadzona z konkretnych tez, analiz i argumentów jest rezultatem konstruktywistycznego myślenia badaczki, jej potrzeby syntezy, uogólnienia, wynika natomiast z doświadczenia naukowego opartego na jej praktykach badawczych i komunikacyjnych. Cyfrowa semiopoetyka jako praca o komunikacji hiperliterackiej jest też książką o ontycznych podstawach dyskursów społecznych. Zgadzam się z tezą nadrzędną badaczki, że ontyczna złożoność znaku cyfrowego przekształca wszystko, co zależy od mediów digitalnych, a więc nie tylko teksty literackie i modelujące je poetyki, lecz teksty i dyskursy funkcjonujące na wielu poziomach ludzkiej aktywności w skali mikro- i makrospołecznej. Cyfrowość zmienia humanistykę, a monografia Ewy Szczęsnej pokazuje, jak technologie digitalne stają się szansą dla humanistyki gotowej na zmiany społeczne, kulturowe.

Znak cyfrowy jest znakiem uwarunkowanym technologicznie, dlatego tak ważne w koncepcji Autorki jest uwzględnienie konstytutywnej dychotomii (i licznych jej odmian opisanych w książce) między programowaniem i użytkowaniem. Dlatego, kiedy czytamy: „można łatwo wykazać, że na poziomie programowania informacja strukturalna jest ważniejsza niż informacja tekstowa" (s. 127), to rozumiemy, że ta hipoteza z czegoś wynika i do czegoś prowadzi. Przytoczony cytat pochodzi z dociekań dotyczących semiosfery digitalnej i odnosi się do jednej z jej najważniejszych własności, czyli do relacyjności (s. 127). Badaczka wielokrotnie łączy w swoim namyśle analizę 
szczegółu (np. budowa znaku) z syntezą całości (np. semiosfera digitalna). Przyjęcie założenia o istnieniu znaku cyfrowego nie wyklucza innych teorii znaku, lecz wskazuje na ich funkcjonalne i operacyjne ograniczenia, a zatem jest to koncepcja komplementarna wobec wcześniejszych.

Książka Ewy Szczęsnej wymaga uważnej lektury. Nie jest tak, że wszystkie przedstawione w niej rozpoznania należy przyjmować bezkrytycznie, a czytając książkę wiemy, że nie to jest celem Autorki, której traktat jest otwarty na polemikę. Podam przykład. Kiedy badaczka pisze, że to, co w kulturze przedcyfrowej „opisywane jest jako hybrydyczne czy szerzej - heterogeniczne, w sferze kultury cyfrowej funkcjonuje jako tożsame i spójne" (s. 178). Badaczka nie podaje definicji pojęcia „hybrydyczności”, choć okazuje się ono istotne w dociekaniach dotyczących strategii znaczeniotwórczych. Domyślamy się, że hybrydyczność zawiera się w heterogeniczności, gdyż taki wniosek można wysnuć na podstawie zacytowanego zdania. Czym w tym kontekście jest jednak hybrydyczność? Różnorodnością tekstów ze względu na genologię, treści, a może jest to połączenie tego, co odmienne wyłącznie na poziomie medium lub technologii? Ewa Szczęsna pisze, że na ekranie komputera każda informacja znakowa ma tę samą wartość semiotyczną - należy do tego samego systemu: „W wyniku cyfrowej remediacji przedstawienia, które dotychczas miały różny status bytowy, łączone zaś tworzyły formy hybrydyczne, teraz mają tę samą ontyczność, przy zachowaniu odmienności w sferze zewnętrznej reprezentacji" (s. 179). Oznacza to, że digitalizacja każdego kodu komunikacyjnego ${ }^{3}$ powoduje, iż na poziomie oprogramowania przekaz jest określonym układem zerojedynkowym. To założenie jest zgodne z podstawową tezą odnoszącą się do znaku cyfrowego. Czym jednak jest „odmienność" w tym kontekście? Hybrydyczność w epoce przedcyfrowej, o której wspomniano, kojarzy się z łączeniem tego, co odmienne, natomiast w toku wywodu pola semantyczne obydwu pojęć („hybrydyczności” i „odmienności”) są rozłączne, nie powinny się więc dookreślać nawet konceptualnie. Uważam, że z perspektywy funkcji przekazu i postaw użytkownika jednak dalej mamy do czynienia z hybrydami, tym bardziej że użytkownik cyfrowego medium nie działa w komunikacyjnej próżni, wszak tożsame ontycznie przekazy są różnorodne dyskursywnie, interfejs komputera utrwala tę różnorodność dyskursywną - tworząc na poziomie komunikacji audiowizualnej hybrydę

3 Philippe Codognet, twierdzi, że digitalizacja kodów wizualnych jest jednym z ważniejszych momentów w rozwoju mediów cyfrowych. Por. Ph. Codognet The Semiotics of the Web, http:// pauillac.inria.fr/ codognet/web.htm (29.02.2020). 
wielokodową, co jest widoczne np. w trakcie równoczesnego korzystania z różnych stron portali społecznościowych.

Cyfrowa semiopoetyka jest przykładem na odpowiedzialne uprawianie koniecznej poznawczo humanistyki. W zakończeniu monografii Ewa Szczęsna pisze: „Mówić o humanistyce jako o nieprzydatnej dla gospodarki i technologii, pozbawionej techniczno-innowacyjnego potencjału, skazanej na marginalizację, to znaczy nie rozumieć jej istoty. Działać na rzecz takiej marginalizacji to hamować rozwój dziedzin, w których imieniu to działanie się podejmuje - to po prostu im szkodzić" (s. 404). W zacytowanym fragmencie wyrażona jest troska nie tylko o humanistykę, ale po prostu o naukę i o jej autonomię. Cyfrowa semiopoetyka jest udaną afirmacją zmiany cywilizacyjnej, chciałoby się powiedzieć: Studia humaniora reformata et reformanda sunt.

\section{Abstract}

\section{Marek Kaźmierczak}

ADAM MICKIEWICZ UNIVERSITY (POZNAŃ)

The Affirmation of Change: The Impact of Digital Technology on Literary Theory

In this is the review of Ewa Szczęsna's book Digital Semiopoetics Kaźmierczak focuses on key themes such as the digital sign, text and discourse. He also refers to the new discipline called "digital semiopoetics".

\section{Keywords}

digital sign, text, discourse, digital semiopoetics, communication 